\title{
JURNAL PERILAKU HARIAN HARIMAU SUMATERA (Panthera tigris sumatrae) DI TAMAN MARGASATWA DAN BUDAYA KINANTAN BUKITTINGGI SUMATERA BARAT
}

\author{
(Journal Daily Behavior of Sumatran Tigers (Panthera tigris sumatrae) at Kinantan \\ Cultural and Wildlife Park Bukittinggi West Sumatra)
}

\author{
Muhammad Atha Khalis ${ }^{1}$, Ulfa Hansri Ar Rasyid ${ }^{1}$, Erdiansyah Rahmi ${ }^{1 *}$ \\ ${ }^{1}$ Program Studi Kehutanan, Fakultas Pertanian, Universitas Syiah Kuala \\ email: erdian.ersan@unsyiah.ac.id
}

\begin{abstract}
Abstrak. Menurut IUCN (International Union for Conservation of Nature) harimau sumatera masuk kedalam kategori terancam punah (Critical endangered). Harimau sumatera termasuk salah satu hewan dengan tingkat perawatan yang sulit dan sangat rawan kematian. Kematian tersebut tak terkecuali di wilayah kawasan $e x$-situ. Penelitian ini menggunakan metode observsi dan Focal animal sampling yang dilakukan dari pukul 08.00 sampai dengan pukul 17.00 WIB. Persentase perilaku harian harimau sumatera secara umum di Taman Margasatwa dan Budaya Kinantan (TMSBK) yaitu Boncel melakukan perilaku bergerak (43\%), istirahat (39\%), individu (12\%), sosial (3\%) dan agonistik (3\%). Perilaku yang dilakukan Bujang Kinantan yaitu perilaku bergerak (17\%), istirahat (64\%), individu (14\%), sosial (1\%) dan agonistik (3\%). Perilaku Bancah selama pengamatan yaitu perilaku bergerak (12\%), istirahat (62\%), individu (17\%), sosial (10\%) dan agonistik (0\%). Perilaku Dara Jingga yaitu perilaku bergerak (5\%), istirahat (79\%), individu (15\%), sosial (1\%) dan agonistik $(0 \%)$. Berdasarkan persentase perilaku harian harimau yang diperoleh dapat dilihat bahwasanya perilaku istirahat lebih dominan tinggi pada tiap individu, tetapi pada harimau Boncel memiliki persentase perilaku bergerak yang dominan, dikarenakan umur Boncel terbilang masih muda.
\end{abstract}

Kata kunci : Harimau sumatera, Perilaku harian, Konservasi, Focal animal sampling.

\begin{abstract}
According to the IUCN (International Union for Conservation of Nature), the Sumatran tiger is in the critically endangered category. The Sumatran tiger is one of the animals with a difficult level of care and is very prone to death. These deaths are no exception in the ex-situ area. This research used observation method and Focal animal sampling which was conducted from 08.00 to 17.00 WIB. The percentage of daily behavior of Sumatran tigers in general at the Kinantan Wildlife and Culture Park (TMSBK) is that Boncel engages in moving behavior (43\%), resting (39\%), individual (12\%), social (3\%) and agonistic (3\%). The behavior of Bujang Kinantan is moving behavior (17\%), resting (64\%), individual (14\%), social (1\%) and agonistic (3\%). Bancah's behavior during the observation was moving behavior (12\%), resting (62\%), individual (17\%), social $(10 \%)$ and agonistic $(0 \%)$. Dara Jingga's behavior is moving behavior (5\%), resting (79\%), individual (15\%), social $(1 \%)$ and agonistic $(0 \%)$. Based on the percentage of daily behavior of tigers obtained, it can be seen that resting behavior is more dominant in each individual, but the Boncel tiger has a dominant percentage of moving behavior, because Boncel's age is relatively young.
\end{abstract}

Keywords: Sumatran tiger, Daily behavior, Conservation, Focal animal sampling.

\section{PENDAHULUAN}

Harimau (Pantera tigris) merupakan salah satu predator terbesar yang penyebarannya dahulu hampir meliputi seluruh daratan Asia hingga beberapa pulau di Indonesia. Harimau merupakan satwa teresterial yang menempati beragam tipe habitat, di antaranya hutan tropis, mangrove, hutan rawa gambut dan hutan musim. Dinerstein et al. (2006) memperkirakan bahwa habitat harimau di dunia yang tersisa tinggal sebesar 7\% dari total habitat berdasarkan sejarah geografi penyebarannya. Hal tersebut menunjukkan bahwa penyebaran populasi harimau di alam menurun secara drastis dan sampai sekarang masih berlangsung pengurangan luas habitat untuk berbagai kepentingan. Indonesia pernah memiliki tiga dari delapan subspesies harimau yang ada di dunia, namun dua diantaranya, yaitu harimau jawa (Panthera tigris sondaica) dan harimau bali (Panthera tigris balica) telah dinyatakan punah, masing-masing pada tahun 1940-an dan 1980-an. 
Menurut IUCN (International Union for Conservation of Nature) harimau sumatera masuk kedalam kategori terancam punah (Critical endangered). Harimau sumatera merupakan salah satu satwa dengan tingkat perawatan yang sulit dan sangat rawan kematian. Kematian tersebut tak terkecuali terjadi di ex-situ. Kawasan ex-situ di Indonesia belum mampu menjamin kesejahteraan harimau, beberapa memiliki ukuran kandang yang kecil dan tidak mampu mencukupi kebutuhan pakan karena harga pakan yang mahal (Fuadi, 2019). Namun upaya pelestarian secara ex-situ perlu dipertahankan untuk menyiasati kebutuhan satwa di habitat aslinya yang semakin berkurang. Kegiatan konservasi ex-situ harus terus ditingkatkan dan dievaluasi untuk meningkatkan jumlah harimau yang bertahan hidup dan mampu berkembang biak tergantung pada tingkat kesejahteraan hidupnya (Yolanda et al., 2017).

Taman Margasatwa dan Budaya Kinantan, bukittinggi sejak bulan Januari 2021 telah membuat kandang baru untuk hariamau sumatera (Panthera tigris sumatrae) dari kandang tertutup ke kandang baru berupa kandang peraga (enclosure) yang jauh lebih luas dan dibuat semi-hutan yang membuat aktivitas menjadi lebih leluasa dibandingkan dengan kandang tertutup, hal ini tentunya akan berpengaruh terhadap perilaku harimau sumatera. Informasi mengenai perilaku harian harimau sumatera masih terbatas dan belum pernah dilakukan di Taman Margasatwa dan Budaya Kinantan Bukittinggi, berkaitan dengan hal tersebut maka dilakukan penelitian mengenai perilaku harian individu harimau sumatera di TMSBK agar membantu pengawasan dan penanganan dalam merawat harimau. Terdapat tiga kandang harimau sumatera di Taman Margasatwa dan Budaya Kinantan Bukittinggi (TMSBK), salah satunya memiliki desain yang berbeda dari kedua kandang lainnya. Dimana kandang termasuk dalam jenis kandang terbuka dengan dinding kaca setebal $26 \mathrm{~mm}$ dan dilengkapi sarana sesuai dengan habitat aslinya. Di dalam kandang tersebut terdapat dua harimau jantan. Berbagai macam sarana yang tersedia dapat menimbulkan berbagai perilaku.

Penelitian ini bertujuan untuk mendapatkan informasi perilaku harian harimau sumatera di TMSBK dan diharapkan dapat memberikan informasi perilaku harimau sumatera sehingga dapat dijadikan sebagai dasar dalam pengelolaannya di TMSBK. Hal ini dilakukan guna menjaga dan melestarikan fauna agar tidak punah dan membantu pengawas dalam merawat harimau sumatera agar lebih maksimal.

\section{METODE PENELITIAN}

Metode yang digunakan metode Focal Animal Sampling yaitu pengamatan perilaku menggunakan per-individu satwa sebagai objek pengamatan pada suatu periode tertentu, dengan catatan individu harimau selalu terlihat.

Alat-alat dan bahan yang akan digunakan dalam penelitian ini adalah alat tulis, timer, kamera, dan masker. Objek dalam penelitian ini adalah tiga harimau sumatera jantan dan satu harimau sumatera betina.

\section{Prosedur Kerja}

Pengamatan perilaku harian harimau dilakukan mulai saat harimau didalam kandang kontrol pada pukul 08.00-09.00 WIB dan dikeluarkan dari kandang kontrol (in holding) oleh keeper ke kandang peraga (enclosure) yaitu sekitar pukul 09.00 WIB sampai dengan pukul 17.00 WIB (sore hari) sebelum dimasukkan kembali ke dalam in holding (sesuai jadwal rutinitas di TMSBK). Penelitian ini dilakukan pada setiap individu dengan waktu pencatatan setiap perilaku individu perlima menit pada tabulasi data. 
Data perilaku harian dalam penelitian ini dikelompokkan berdasarkan ethogram/ tabel perilaku yang dibuat untuk mengamati perilaku harimau sumatera yaitu mengamati dan mencatat:

1) Perilaku Bergerak, meliputi perilaku perpindahan harimau objek dari suatu lokasi ke lokasi lainnya dalam areal kandang kurungan terbuka.

a) Move (M) yaitu bergerak dari satu titik ke titik lainnya.

b) Climb (C) yaitu dilakukan dengan menaiki batang pohon atau tempat yang lebih tinggi dari dataran

2) Perilaku Istirahat, meliputi kondisi harimau tidak melakukan perilaku/ aktivitas apapun atau saat harimau diam.

a) Duduk ( $\mathrm{Si}$ ) yaitu saat harimau pada posisi seperti berbaring dengan kepala tegak

b) Berbaring (Ld) yaitu saat semua tubuh harimau ke tanah.

c) Tidur ( $\mathrm{Sl}$ ) yaitu istirahat total / menutup mata

d) Berdiri diam ( $\mathrm{St}$ ) yaitu memposisikan tubuh tegak bertumpu pada keempat kaki.

3) Perilaku individu, yaiu perilaku aksi sendiri atau kegiatan yang dilakukan tanpa bantuan individu lain.

a) Makan (E) yaitu perilaku harimau dalam kondisi membidik, mengintai dan menerkam makanan

b) Minum (D) yaitu kegiatan saat harimau minum di air yang tersedia.

c) Bermain $(\mathrm{P})$ yaitu aksi bermain sendiri dengan memanfaatkan objek yang ada.

d) Defekasi (DF) yaitu kegiatan mengeluarkan kotoran feses

e) Urinasi (UR) yaitu kegiatan mengeluarkan air urin

f) Grooming (Gr) yaitu kegiatan menggaruk tubuh dan menjilat tubuh

g) Typical (Ty) yaitu kegiatan mengaum

4) Perilaku Sosial (S) yaitu perilaku saling melakukan aksi/ interaksi harimau dengan harimau lainnya, harimau dengan keeper, maupun harimau dengan pengunjung.

5) Perilaku Agonistik (Ag) yaitu perilaku terkait dengan sifat agresif dan pertarungan yang dilakukan harimau, meliputi perilaku mengejar, merebut makanan/minuman, dan berkelahi.

\section{Analisis Data}

Analisis perilaku harian dilakukan dengan menggunakan analisis deskriptif yaitu dengan menjabarkan hasil pengamatan mengenai perilaku harian harimau sumatera berdasarkan data yang berupa tabel. Selain itu, terdapat pula analisis perhitungan persentasi perilaku harian dengan menggunakan persamaan menurut Martin and Bateson (1993) :

$$
\% \text { Perilaku : } \frac{\text { Subkategori perilaku }}{\text { Total kategori perilaku }} \times 100 \%
$$

Perbandingan perilaku juga dilakukan dengan memperhatikan perbedaan perbedaan jenis perilaku, durasi perilaku dan perilaku dominan harimau sumatera.

\section{HASIL DAN PEMBAHASAN}

\section{Harimau yang dijadikan objek penelitian}

Harimau sumatera yang dijadikan objek penelitian terdiri dari tiga harimau jantan dan satu harimau betina. Setiap harimau memiliki ciri-ciri yang berbeda antar individunya. Ciri fisik yang dapat diamati pada harimau sumatera antara lain terdiri dari ukuran tubuh, bentuk anggota tubuh, motif loreng harimau, dan kelengkapan anggota tubuh. 
Deskripsi ciri fisik atau morfologis dari harimau sumatera di Taman Margasatwa dan Budaya Kinantan, umur harimau, berat badan dan jenis kelaminnya dapat dilihat pada Tabel 1.

Tabel 1. Harimau yang dijadikan objek penelitian

\begin{tabular}{|c|c|c|c|c|c|c|}
\hline No & Nama & $\begin{array}{l}\text { Jenis } \\
\text { Kelamin }\end{array}$ & Umur & $\begin{array}{l}\text { Tempat } \\
\text { dilokasi }\end{array}$ & $\begin{array}{l}\text { Berat } \\
\text { Badan }\end{array}$ & Ciri Fisik \\
\hline 1 & Bancah & Jantan & 20 tahun & $\begin{array}{l}\text { Kandang } \\
\text { peraga lama }\end{array}$ & $110 \mathrm{~kg}$ & $\begin{array}{l}\text { a.Bentuk badan normal } \\
\text { b. Warna loreng terlihat } \\
\text { jelas } \\
\text { c. Warna tubuh oranye } \\
\text { kecoklatan cerah } \\
\text { d. Kaki kiri belakang } \\
\text { buntung karena jerat }\end{array}$ \\
\hline 2 & $\begin{array}{l}\text { Dara } \\
\text { Jingga }\end{array}$ & Betina & 16 tahun & $\begin{array}{l}\text { Kandang } \\
\text { peraga lama }\end{array}$ & $100 \mathrm{~kg}$ & $\begin{array}{l}\text { a. Bentuk badan normal } \\
\text { b. Warna loreng kurang } \\
\text { jelas } \\
\text { c. Warna tubuh oranye } \\
\text { kecoklatan sedikit gelap } \\
\text { d.Tidak ada luka fisik }\end{array}$ \\
\hline 3 & Boncel & Jantan & 3 tahun & $\begin{array}{l}\text { Kandang } \\
\text { peraga baru }\end{array}$ & $90 \mathrm{~kg}$ & $\begin{array}{l}\text { a.Bentuk badan normal } \\
\text { b.Warna loreng terlihat } \\
\text { jelas } \\
\text { c.Warna tubuh oranye } \\
\text { kecoklatan gelap } \\
\text { d.Tubuh lebih kecil dari } \\
\text { yang lainnya }\end{array}$ \\
\hline 4 & $\begin{array}{l}\text { Bujang } \\
\text { kinantan }\end{array}$ & Jantan & 4 tahun & $\begin{array}{l}\text { Kandang } \\
\text { peraga baru }\end{array}$ & $110 \mathrm{~kg}$ & $\begin{array}{l}\text { a.Bentuk badan normal } \\
\text { b.Warna loreng kurang } \\
\text { jelas } \\
\text { c. Warna tubuh oranye } \\
\text { kecoklatan gelap } \\
\text { d.Memiliki bercak putih } \\
\text { di sekitar tubuh }\end{array}$ \\
\hline
\end{tabular}

Berikut adalah penampilan dari masing-masing individu harimau yang diamati di Taman Margasatwa dan Budaya Kinantan pada gambar 1 yaitu Boncel, Bujang Kinantan, Bancah, Dara Jingga.

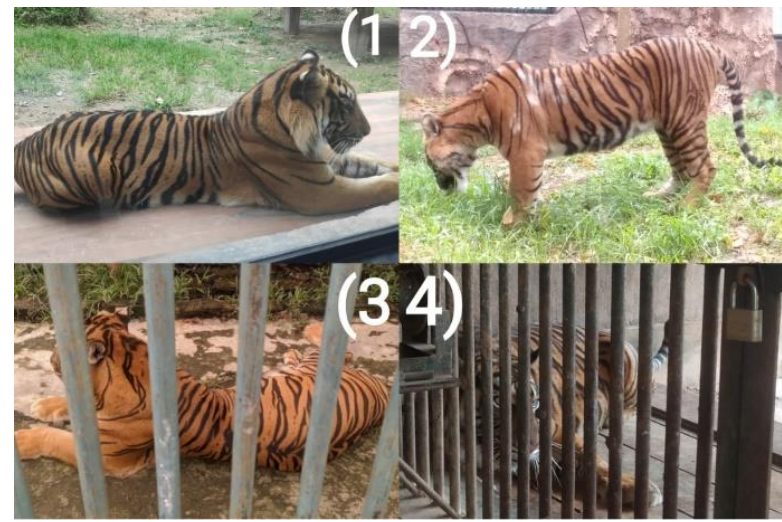

Gambar 1. Foto perbandingan (1) Boncel (2) Bujang Kinantan (3) Bancah (4) Dara Jingga 


\section{Jenis, Jumlah, dan Frekuensi Pakan}

Syarat pakan bagi satwa diantaranya adalah pakan harus bersih, segar, bebas dari kontaminasi, cocok, dan sesuai dengan selera satwa, tidak menimbulkan gangguan metabolisme, pakan harus dalam jumlah yang cukup, mutu baik, seimbang, serta bervariasi (Parakkasi, 1999). Ada dua jenis pakan yang diberikan untuk harimau sumatera di TMSBK yaitu daging dan ayam. Menurut Firdilasari et al. (2016), jenis pakan yang bervariasi sangat penting dalam menunjang kecukupan gizi, kesehatan, dan mencegah kebosanan terhadap pakan yang diberikan. Dalam penelitian Felisia (2014) pakan harimau sumatera yang diberikan berupa daging kambing, daging kuda, dan daging yang didatangkan dari Australia, sedangkan daging ayam didapatkan dari peternak di sekitar TSI (Taman Safari Indonesia). Sedangkan dalam penelitian Fauzia (2015) menambahkan bahwa pakan utama harimau sumatera di Kebun Binatang Bandung yaitu daging sapi dan karkas ayam.

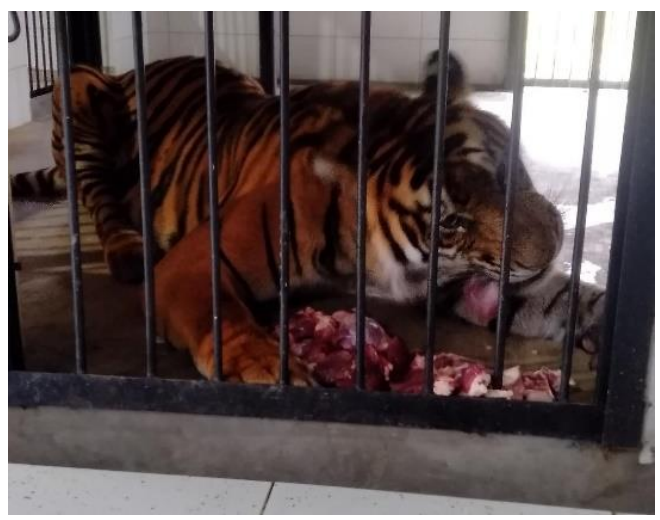

Gambar 2. Perilaku makan harimau sumatera

Pakan harimau sumatera diberikan $\pm 4 \mathrm{~kg}$ perhari pada setiap individu baik daging kambing maupun ayam secara bergantian. Setiap satu minggu sekali yaitu pada hari jum'at, harimau tidak diberikan makan atau puasa makan dengan tujuan mengontrol nafsu makan serta mencegah satwa dari obesitas

Tabel 2. Jenis, jumlah, dan frekuensi pakan

\begin{tabular}{llll}
\hline No. & Jenis & Jumlah & \multicolumn{1}{c}{ Frekuensi/waktu pemberian } \\
\hline 1 & Daging kambing & $\pm 4 \mathrm{~kg}$ & $\begin{array}{l}\text { Perindividu 1x sehari pada hari rabu dan } \\
\text { minggu }\end{array}$ \\
\hline 2 & Ayam & $\pm 4 \mathrm{~kg}$ & $\begin{array}{l}\text { Perindividu 1x sehari pada hari senin, } \\
\text { selasa, kamis, sabtu }\end{array}$
\end{tabular}

\section{Spesifikasi Kandang}

Ada dua jenis kandang di TMSBK yaitu kandang kontrol dan kandang peraga, dapat dilihat pada tabel 3 salah satunya kandang harimau sumatera yang di desain berbentuk semi hutan, berdinding kaca setebal $26 \mathrm{~mm}$, sehingga pengunjung dapat berinteraksi lebih dekat dengan satwa.

Tabel 3. Jenis, ukuran, fungsi dan sarana kandang harimau sumatera.

\begin{tabular}{llllrll}
\hline Jenis & Jumlah & Ukuran & Fasilitas & Kontruksi & \multicolumn{2}{l}{ Fungsi } \\
kandang & kandang & Kandang & Kandang & Kandang & Kandang \\
\hline $\begin{array}{l}\text { Kandang } \\
\text { kontrol }\end{array}$ & 3 & $4 \times 4 \times 4$ & tempat & tidur, & Lantai & Tidur dan \\
wadah minum, & dasarnya & melakukan \\
\hline
\end{tabular}




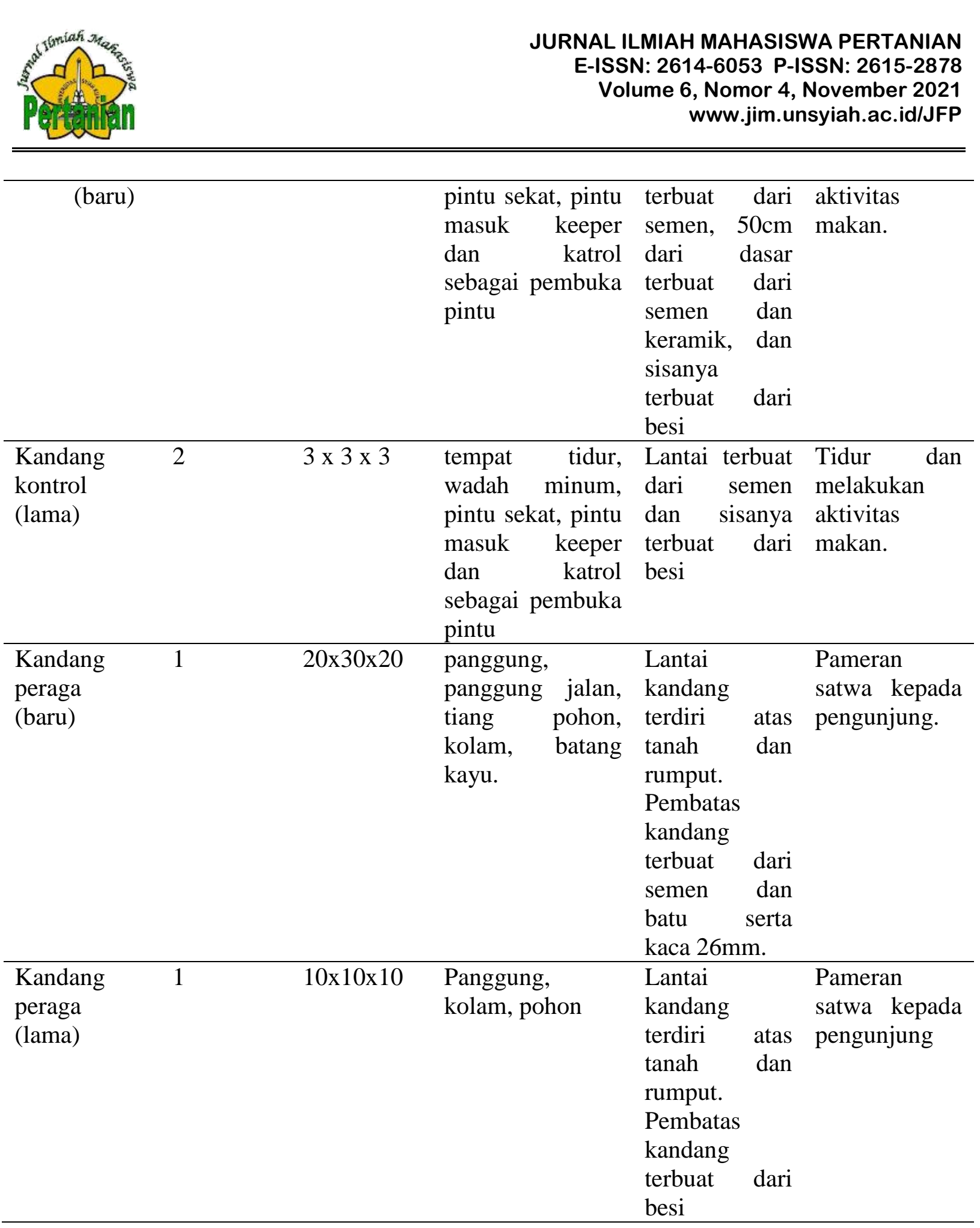

\section{Perilaku Harian Individu Harimau Secara Umum di TMSBK}

Hasil penelitian yang telah dilakukan terhadap perilaku harian empat individu harimau sumatera yaitu Boncel harimau jantan (3 tahun), Bujang Kinantan harimau jantan (4 tahun), Bancah harimau jantan (20 tahun) dan Dara Jingga harimau betina (16 Tahun) dikelompokkan menjadi lima kategori perilaku harian yang menunjukkan persentase frekuensi yang bervariasi pada masing-masing kategori perilaku. Persentase frekuensi perilaku harian individu Boncel, Bujang Kinantan, Bancah dan Dara Jingga secara umum di TMSBK.

Frekuensi perilaku harian empat harimau sumatera di TMSBK lebih dominan melakukan istirahat. Persentase perilaku harian harimau sumatera secara umum yaitu Boncel melakukan perilaku bergerak (43\%), istirahat (39\%), individu (12\%), Sosial (3\%) dan agonistik (3\%). Perilaku yang dilakukan Bujang Kinantan yaitu perilaku bergerak (17\%), 
istirahat (64\%), individu (14\%), Sosial (1\%) dan agonistik (3\%). Perilaku Bancah selama pengamatan yaitu perilaku bergerak (12\%), istirahat (62\%), individu (17\%), Sosial (10\%) dan agonistik (0\%). Dan perilaku Dara Jingga yaitu perilaku bergerak (5\%), istirahat (79\%), individu (15\%), Sosial (1\%) dan agonistik (0\%). Perilaku istirahat merupakan perilaku paling banyak yang dilakukan harimau sumatera di TMSBK seperti duduk, berbaring, tidur dan berdiri diam.

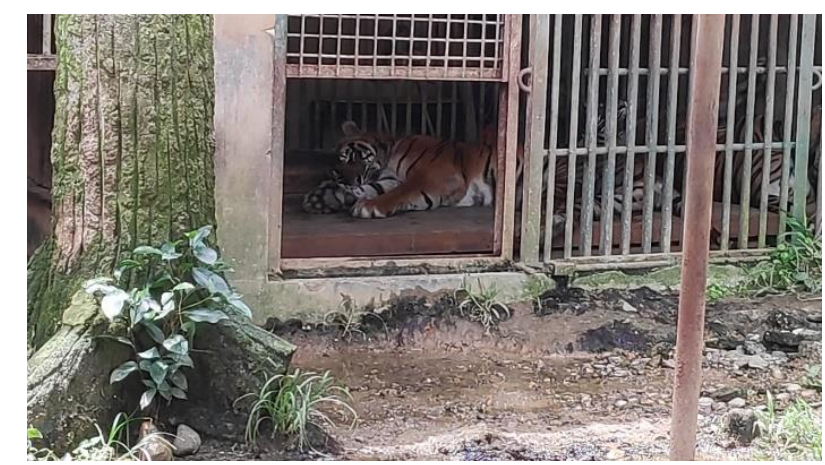

Gambar 3. Bancah dan dara jingga melakukan perilaku istirahat

Perilaku bergerak yang dilakukan yaitu saat harimau sumatera bergerak dari satu titik ke titik yang lainnya dengan cara berjalan santai, mondar-mandir, memanjat atau bergerak untuk berpindah. Dilihat dari persentase perilaku individu bergerak yang terbesar ialah harimau boncel yang mencapai $43 \%$, karena boncel ketika masih kecil dibutuhkan perawatan khusus dengan seiringan waktu boncel menjadi dekat dengan keeper. Maka dari itu harimau boncel sering berjalan atau mondar-mandir di kandang peraga dan lebih sering terlihat di kaca yang dikhususkan untuk melihat harimau, tidak seperti harimau lainnya yang bersembunyi dan istirahat untuk mengindari manusia.

Perilaku individu harimau di TMSBK sebesar 12\%-17\% yang meliputi makan, minum, grooming, urinasi, bermain dan mengaum. Frekuensi perilaku individu mendekati sifat alamiah harimau pada habitat alami yaitu soliter atau hidup menyendiri atau berpasangan. Perilaku sosial harimau adalah interaksi harimau dengan individu lain, keeper maupun pengunjung. Persentase perilaku sosial secara umum di TMSBK sebesar 1\%-10\%. Rendahnya persentase sosial harimau di TMSBK menujukkan bahwa sifat alamiah harimau yang bersifat soliter masih terlihat disini. Di alam liar perilaku sosial hanya dilakukan jika harimau hendak kawin dan dilihat dari perilaku sosial Bancah mencapai 10\% untuk mencaga betina yang sedang hamil. Walaupun perilaku istirahat Bancah yang tinggi tetapi semua dilakukan tidak jauh dari betinanya.

Perilaku agonistik menjadi perilaku yang paling kecil dilakukan hanya mencapai 3\% yang meliputi berkelahi, cakar-cakaran serta kejar-kejaran. Tidak seperti Bancah dan Dara, Boncel dan Bujang Kinantan lah yang melakukan kegiatan agonistik tetapi sangat jarang dilakukan. Dihabitat aslinya kegiatan agonistik dilakukan untuk merebutkan teritori atau merebut mangsa.

\section{KESIMPULAN DAN SARAN}

Dari persentase perilaku harian harimau diatas dapat dilihat bahwasannya perilaku istirahat lebih dominan tinggi, tetapi Boncel memiliki persentase perilaku bergerak yang dominan dikarenakan usia Boncel yang terbilang masih muda. Sedangkan Bancah dan Dara Jingga juga lebih dominan perilaku istirahat dikarenakan Dara Jingga saat penelitian dilakukan sedang bunting 2 bulan, dan Bancah sering melakukan perilaku duduk maupun tidur didekat betina guna untuk menjaga betina dalam bahaya. Adapun saran yang saya berikan untuk TMSBK adalah kandang harimau lainnya masih terlalu kecil, sebaiknya 
kandang harimau lainnya bisa seperti kandang peraga yang baru atau bahkan lebih baik agar harimau lebih maksimal melakukan perilaku hariannya.

\section{DAFTAR PUSTAKA}

Dinerstein, E., C. Loucks, A. Heydlauff, E. Wikramanayake, G. Bryja, J. Forrest, J. Ginsberg, S. Klenzendorf, P. Leimgruber, T. O’Brien, E. Sanderson, J. Seidensticker and M. Songer. 2006. Setting Priorities for the Conservation and Recovery of Wild Tigers: 2005-2015. A

Dwiyani, N. P., Setiati, N. dan Widiyaningrum, P. 2014. Ektoparasit pada ordo artiodactyla di Taman Margasatwa Semarang. Unnes Journal of Life Science, 3(2): 124-129.

Fauzia IP. 2015. Pengelolaan kesejahteraan harimau sumatera dan pemanfaatannya sebagai satwa peraga di Kebun Binatang Bandung, Jawa Barat [skripsi]. Bogor (ID): Institut Pertanian Bogor.

Felisia. 2014. Pengelolaan Penangkaran Harimau Sumatera (Panthera tigris sumatrae Pocock, 1929) di Taman Safari Indonesia Cisarua. Institut Pertanian Bogor. Bogor.

Fuadi, B.F. 2019. Studi Perilaku Harian Harimau Sumatera (Panthera tigris sumatrae Pocock, 1929) Jantan dan Betina di Kawasan konservasi ex-situ Taman Satwa Taru Jurug Surakarta. Universitas Islam Negeri Sunan Kaliaga. Yogyakarta.

Martin P, Bateson P. 1993. Measuring Behaviour. An Introductory Guide. Ed 2. Cambridge (UK): Cambridge University Press.

Parakkasi A. 1999. Ilmu Nutrisi dan Makanan Ternak Ruminan. Jakarta (ID): Universitas Indonesia Press.

Rivanisa, F. P., 2015. Koefisien Inbreeding, Perilaku Harian, dan Ciri Fisik Harimau Sumatera (Panthera tigris sumatrae) di Kebun Binatang Bandung, Jawa Barat. Institut Pertanian Bogor. Skripsi.

Yolanda, Y., Rusdi, R., \& Supiyanti, A. 2017. Kajian Kesejahteraan Harimau Sumatera pada Konservasi Ex-situ di Taman Margasatwa Ragunan dan Taman Margasatwa Bandung. Bioma, 13(2), pp.100-107. 